\title{
Comparative transcriptome analysis of sweet sorghum provides insights into new IncRNAs acting as ceRNAs during salt responses
}

\section{Xi Sun}

Shandong Normal University

Hongxiang Zheng

Shandong Normal University

Jinlu Li

Shandong Normal University

Na Sui ( $D$ suina800101@163.com)

Shandong Normal University

Research article

Keywords: Sweet sorghum, IncRNA, ceRNA network, salt tolerance

Posted Date: October 14th, 2019

DOI: https://doi.org/10.21203/rs.2.16023/v1

License: (a) (i) This work is licensed under a Creative Commons Attribution 4.0 International License.

Read Full License 


\section{Abstract}

LncRNAs can act as competitive endogenous RNAs (ceRNAs) to competitively bind miRNAs, thereby indirectly regulating the transcription levels of other RNA transcripts to confer resistance to plants. But how specific ceRNAs respond to salt stress in sweet sorghum is still unclear. In this study, 126 and 133 differentially expressed IncRNAs were identified in salt-tolerant sweet sorghum (M-81E) and a saltsensitive line (Roma) by high-throughput RNA-seq, respectively. And five new IncRNAs were identified in M-81E and Roma after salt stress treatment, IncRNA13472, IncRNA11310, IncRNA2846, IncRNA26929 and IncRNA14798 acted as ceRNAs to regulate the expression of target genes related to salt resistance by binding the five miRNAs sbi-MIR169b-p3, sbi-MIR5567-p3-2ss16CT17TC, sbi-MIR5567-p5-2, sbiMIR5567-p5-2ss17CT18TC and PC-3p-270284-34, respectively. The target genes mainly included proton pump proteins, transport proteinsantioxidants, signal transduction proteins and transcription factors. However M-81E had more complex ceRNAs network than in Roma, which might be related with its different salt tolerance. In summary, this study identified a new ceRNA network within the transcriptome and revealed the effect of IncRNAs in the salt stress response.

\section{Background}

Salt stress has now become one of the main abiotic stress factors constraining agricultural development worldwide. A considerable amount of arable soil in the world is affected by salinity. When the local topsoil contains a lot of soluble salts, it forms a saline-alkali soil, which causes different degrees of damage to plants and even plant death. Salt stress mainly reduces the quality and quantity of crops by affecting plant growth and metabolism, through ionic stress, osmotic stress, oxidative stress and nutrient stress[1-4].

In recent years, numerous studies have shown that non-coding RNA can enhance the resistance of plants to stress by regulating the expression of plant functional genes [5-9]. Based on their length, non-coding RNAs can be divided into small non-coding RNAs (sncRNA) and long non-coding RNAs (IncRNA). MicroRNA is an important type of small non-coding RNA, and has only 21 nucleotides of single-stranded small RNA in plants [10]. Mature miRNAs can form miRNA-mediated silencing complexes (MIRISCs) with AGO complexes, and then cleave and degrade their target genes, resulting in gene silencing [11]. By contrast, IncRNA refers to non-coding RNAs over $200 \mathrm{nt}$ in length, and there is increasing evidence that IncRNAs are potential regulatory molecules [12]. IncRNAs can act as competing endogenous RNAs (ceRNAs) to competitively bind to the same miRNAs as mRNAs through miRNA response elements (MREs), resulting in changes in target gene expression and thereby conferring resistance to various stresses [13]. In plants, the standard for target mimics is much stricter than in animals and the positive position of the sequence must not conform to the principle of base pairing (resulting in protrusions). Recent studies have shown that IncRNAs can regulate the expression levels of target genes through cisor trans-regulation and can be cleaved by miRNA to generate siRNA to silence target genes. In addition, some natural antisense IncRNAs are involved in the regulation of target gene expression [14-20]. ceRNA 
has been well studied in animals. However, in plants, current research on the regulatory mechanism of ceRNA still represents the tip of the iceberg.

Sweet sorghum [Sorghum bicolor (L.) Moench], also known as sugar sorghum, is an annual C4 crop of the Gramineae family that has high biomass accumulation and high tolerance to adverse conditions such as salt, drought and flooding [21]. In our previous study, after treatment with $150 \mathrm{mM} \mathrm{NaCl}$ for $24 \mathrm{~h}$, the concentration of $\mathrm{Na}^{+}$in the roots and shoots of $\mathrm{M}-81 \mathrm{E}$ was lower than that in Roma, and the $\mathrm{Na}^{+}$ content in both shoots was much lower than that in the roots. It shows that the root plays a very good role in limiting the transport of $\mathrm{Na}^{+}$to reduce the ionic toxicity caused by salt stress. Similarly, the growth of Roma root was significantly inhibited under salt stress, but M-81E was not. M-81E showed more tolerance to salt stress than Roma. The transcriptional profiles of leaves and roots revealed some of the salt tolerance mechanisms of sweet sorghum $[22,23]$. However, the regulatory mechanism of salt tolerance by ceRNA in sweet sorghum is still unclear. To better understand the dynamic process of salt tolerance and the regulatory mechanism of non-coding RNA, we analyzed the root transcriptome of a salttolerant sweet sorghum line $(\mathrm{M}-81 \mathrm{E})$ and a salt-sensitive line (Roma) through high-throughput Illumina RNA sequencing (RNA-seq). By comparing the transcriptomes of the two sweet sorghum strains under salt stress, we identified differentially expressed IncRNAs, miRNAs and mRNAs, and constructed ceRNA networks related to differentially expressed mRNAs for network analysis. The results of this study provide a deeper understanding of the complex regulatory networks underlying the tolerance of sweet sorghum to salt stress.

\section{Methods}

\section{Plant material and salt treatment}

According to our previous research [22], we selected two sweet sorghum inbred lines, the salt-tolerant strain M-81E and salt-sensitive strain Roma, as experimental materials for subsequent experiments such as RNA extraction and RNA-seq. Following Yang et al. ${ }^{23}$, seeds of the two sweet sorghum strains were cultured at a light intensity of $600 \mu \mathrm{mol} \mathrm{m} \mathrm{m}^{-2} \mathrm{~s}^{-1}\left(15 \mathrm{~h}\right.$ photoperiod) and $70 \%$ relative humidity at $28 \pm 3^{\circ} \mathrm{C}$ (day/night). Previous studies have shown that $150 \mathrm{mM} \mathrm{NaCl}$ is an appropriate concentration that results in a significant difference in physiological parameters between $\mathrm{M}-81 \mathrm{E}$ and Roma [22]. Therefore, at the three-leaf phase, we started to water the plants with nutrient solutions containing 0 and $150 \mathrm{mM} \mathrm{NaCl}$. In the experimental group, the $\mathrm{NaCl}$ concentration was increased by $50 \mathrm{mM}$ every $12 \mathrm{~h}$ up to the final concentration. The plants were used in subsequent experiments after treatment with $150 \mathrm{mM} \mathrm{NaCl}$ for 24 h.

\section{RNA sequencing and whole transcriptome library construction}


Total RNA was extracted using Trizol reagent (Invitrogen, CA, USA) according to the manufacturer's protocol. The total RNA amount and purity were analyzed using a Bioanalyzer 2100 and RNA 6000 Nano LabChip Kit (Agilent, CA, USA) with a RIN value $>7.0$. Libraries of small RNAs $<50 \mathrm{nt}$ was prepared using approximately $1 \mu \mathrm{g}$ of total RNA according to the protocol of the TruSeq Small RNA Sample Preparation Kit (Illumina, San Diego, USA). According to the manuscript of the Epicentre Ribo-Zero Gold Kit (Illumina, San Diego, USA), approximately $10 \mu \mathrm{g}$ of total RNA was used to consume ribosomal RNA, and then purified and fragmented, using the mRNA-Seq sample preparation kit (Illumina, San Diego, USA) Reverse transcribed cleavage of RNA fragments to generate de-RNA strand-specific de-RNA > 200 nt. Then, singleend sequencing was performed on the Illumina Hiseq 2500 and Illumina Hiseq 4000 at LC-BIO (Hangzhou, China). The SE50 strategy was used for the small RNA library and the 150PE on-board strategy was used for the de-RNA chain-specific library.

\section{Assembly and identification of IncRNAs}

First, we used Cutadapt to clean the reads, then use FastQC

(http://www.bioinformatics.babraham.ac.uk/projects/fastqc/) to verify the sequence quality. The reads were mapped to the assembled transcripts of the sweet sorghum genomic sequence using Bowtie2 and Tophat2, and assembled with StringTie [24], which excluding known transcripts encoding proteins and $<200$ bp transcripts $[25,26]$. We then used $\mathrm{CPC}, \mathrm{CNCl}$ and Pfam to predict transcripts with coding potential. We discarded all transcripts with a $\mathrm{CPC}$ score $<-1$ and a $\mathrm{CNCl}$ score $<0$, and considered the remaining transcripts with the class codes $(i, j, o, u, x)$ to be IncRNAs $[27,28]$.

\section{Analysis of DEGs and DELs}

StringTie was used to calculate Fragments Per Kilobase of exon model per Million mapped fragments (FPKM) values to represent the expression levels of genes and IncRNAs [24]. Then, DEGs and DELs were selected using the R package Ballgown with $\log _{2}(\mathrm{fc})>1$ or $<-1$ and $p$-value $<0.05$ [29].

\section{Predicting and analyzing IncRNA-miRNA-mRNA relationship pairs}

IncRNA-miRNA-mRNA relationships were predicted using StarBase (http://starbase.sysu.edu.cn/). Predictions are usually made according to the following rules. (1) The middle of the miRNA is complementary to the base of the IncRNA, but this position produces a 3 to 5 -nt base bulge on the IncRNA. (2) No more than four total mismatches are allowed in the non-intermediate region of each miRNA, and consecutive mismatches should not exceed two nucleotides. (3) No protrusions are allowed in the non-intermediate region of the miRNA. Then, Cytoscape (http://www.cytoscape.org/) was used to construct a putative interaction network. 


\section{Quantitative real-time PCR analysis}

The relative expression levels of IncRNAs, miRNAs and mRNAs were analyzed by qRT-PCR. A total plant RNA extraction kit (Hua Yueyang, Beijing, China) was used on samples of M-81E and Roma treated with 0 and $150 \mathrm{mM} \mathrm{NaCl}$ for $24 \mathrm{~h}$ according to the manufacturer's protocol [22]. Total RNA was isolated from the primary root. The RNA was quantified using a Nanodrop-ND-1000 spectrophotometer (Thermo Fisher Scientific, Wilmington, DE, USA). The sweet sorghum actin gene was used as an endogenous reference gene for IncRNAs and mRNAs, and U6 was used as an endogenous reference gene for miRNAs. We used the stem-loop method to reverse-transcribe miRNAs. Primer sequences are listed in Supplemental Table 2.

\section{Results}

\section{High-throughput sequencing and DEG analysis}

The whole-transcriptome sequencing included three biological replicates of each sample (M-81E-CK1, M-81E-CK2, M-81E-CK3, M-81E-salt1, M-81E-salt2, M-81E-salt3, Roma-CK1, Roma-CK2, Roma-CK3, Roma-salt1, Roma-salt2, Roma-salt3). Single-end sequencing on the Illumina Hiseq 2500 and paired-end sequencing on the Illumina Hiseq 4000 were used to generate more than $363,000,000$ raw reads from the four samples. A total of approximately $54.5 \mathrm{G}$ of raw reads and $53.7 \mathrm{G}$ of valid reads were detected (Table S1). As shown in Table S1, more than $98 \%$ of the raw reads were valid reads. To assess the quality of the RNA-seq data, fast QC was used to assign a quality score $(\mathrm{Q})$ to each base in the reads with a phred-like algorithm [30], and the analysis showed that the data was highly reliable.

After mapping to the sweet sorghum genome, about $86.14 \%, 84.93 \%, 80.62 \%$ and $87.53 \%$ of reads were mapped in the M-81E-CK, M-81E-salt, Roma-CK, and Roma-salt samples, respectively, and over $74.59 \%$, $72.44 \%, 69.04 \%$ and $76.17 \%$ were unique mapped reads (Table. S1). The set of unique mapped reads was mapped to exons $(94.14 \%$ of M-81E-CK, $94.04 \%$ of M-81E-salt, $93.64 \%$ of Roma-CK and $94.10 \%$ of Roma-salt), introns ( $4.72 \%$ of M-81E-CK, $4.78 \%$ of M-81E-salt, $5.14 \%$ of Roma-CK, $4.65 \%$ of Roma-salt) and intergenic regions $(1.14 \%$ of $\mathrm{M}-81 \mathrm{E}-\mathrm{CK}, 1.18 \%$ of $\mathrm{M}-81 \mathrm{E}-\mathrm{salt}, 1.22 \%$ of Roma-CK, $1.25 \%$ of Romasalt) (Fig. 1a). The above results indicate that IncRNA in sweet sorghum is mainly derived from exon transcripts.

After calculating the expression level of each gene (FPKM), 714 genes were found to be significantly differentially expressed $\left(\log _{2}(\mathrm{fc}) \leq-1\right.$ or $\geq 1, p$-value $\left.<0.05\right)$ between $\mathrm{M}-81 \mathrm{E}-\mathrm{CK}$ and M-81E-salt. Among them, 293 differentially expressed genes (DEGs) were up-regulated and 421 DEGs were downregulated. Similarly, 1331 DEGs were detected between Roma-CK and Roma-salt, of which 623 were upregulated and 708 were down-regulated (Fig. 1b).

A Venn diagram of the DEGs showed that 228 genes in M-81E and 588 genes in Roma were uniquely upregulated and that 47 up-regulated genes were co-expressed in the M-81E and Roma samples. Among the down-regulated genes, 331 were M-81E-specific, 611 were Roma-specific, and 97 were co-expressed 
in both $\mathrm{M}-81 \mathrm{E}$ and Roma. In addition, 31 genes were down-regulated in Roma and up-regulated in $\mathrm{M}-$ $81 \mathrm{E}$ and 13 genes were down-regulated in M-81E and up-regulated in Roma (Fig. 1c).

Gene ontology (GO) analysis was performed to assign functional information to the DEGs between the control and NaCl-treated plants. In M-81E, 21,754 genes were assigned 900 Level-2 GO terms, of which 11 significant differences genes with specific $\mathrm{GO}$ were related to salt stress responses. By comparison, in Roma, 21,754 genes were assigned to 1,324 Level-2 G0 terms, of which 31 significant differences genes with specific $\mathrm{GO}$ were associated with salt stress responses. In the Biological Process domain, the "biological process" and "regulation of transcription, DNA-templated" categories were the most prominent in $\mathrm{M}-81 \mathrm{E}$ and Roma. The most highly enriched cell groups in the Cellular Component domain in $\mathrm{M}-81 \mathrm{E}$ and Roma were the nuclear and plasma membrane fractions. In the Molecular Function domain, "molecular function" and "ATP binding" were the most represented GO terms in M-81E, but "molecular function" and "protein binding" were the most represented GO terms in Roma (Fig. S1). The above data indicate that salt stress may affect plants mainly by changing the structure and function of the plasma membrane.

\section{Identification and characterization of IncRNA}

After analysis of all transcripts from the RNA-seq results, annotation and filtration, 2,176 unique IncRNAs were obtained from the $\mathrm{M}-81 \mathrm{E}$ and Roma samples. Moreover, our results showed that these IncRNAs were evenly distributed on the 10 chromosomes in sweet sorghum (Fig. 2a).

Based on the locations of the IncRNAs in the genome of M-81E, 7\% of IncRNAs showed exonic overlap with reference to the opposite strand; $7 \%$ of IncRNAs were transfrags falling entirely within a reference intron; $3 \%$ of IncRNAs were potentially novel isoforms (fragments) with at least one splice junction shared with a reference transcript; $2 \%$ of IncRNAs showed generic exonic overlap with a reference transcript; and $81 \%$ of IncRNAs were unknown and intergenic transcripts. In Roma, 8\% of IncRNAs had exonic overlap with reference to the opposite strand; $8 \%$ of IncRNAs were transfrags falling entirely within a reference intron; $3 \%$ of IncRNAs were potentially novel isoforms (fragments) with at least one splice junction shared with a reference transcript; $2 \%$ of IncRNAs had generic exonic overlap with a reference transcript; and $79 \%$ of IncRNA were unknown and intergenic transcripts (Fig. 2b).

Of these 2,176 IncRNAs, 126 and 133 IncRNAs were specifically expressed in the M-81E and Roma samples, respectively. A total of 126 differentially expressed IncRNAs (DELs) $\left(\log _{2}(\mathrm{fc}) \leq-1\right.$ or $\geq 1, p$ value $<0.05$ ) were identified in the salt-treated $\mathrm{M}-81 \mathrm{E}$ samples compared with the $\mathrm{CK}$ samples, including 71 up-regulated and 55 down-regulated IncRNAs (Fig. 2C). A total of 133 differentially expressed IncRNAs (DELs) $\left(\log _{2}(\mathrm{fc}) \leq-1\right.$ or $\geq 1, p$-value $\left.<0.05\right)$ were identified in the Roma samples, including 68 upregulated and 65 down-regulated IncRNAs (Fig. 2c). 


\section{Analysis of IncRNA-related ceRNA networks in sweet sorghum roots and functional enrichment analysis of related DEGs}

Previous studies have shown that IncRNAs can act as ceRNAs and regulate gene expression after transcription [31, 32]. IncRNAs act as target mimics to absorb miRNA like a sponge and prevent miRNA from completely degrading the target $[14,33,34]$. To assess the regulatory patterns of non-coding RNArelated ceRNA interactions in sweet sorghum roots, we predicted IncRNA-miRNA-mRNA pairs in the experimental and control groups of the two strains using StarBase (http://starbase.sysu.edu.cn/). Then, we used Cytoscape (http://www.cytoscape.org/) to construct a putative interactive network. Consequently, 672 IncRNA-miRNA-mRNA interactions were predicted in the global ceRNA network, of which 477 IncRNA-miRNA-mRNAs were predicted in M-81E (Fig. S2a) and 195 IncRNA-miRNA-mRNA relationship sets were predicted in Roma (Fig. S2b). Thirteen IncRNAs were involved in the 672 IncRNAmiRNA-mRNA regulatory networks, of which seven were in $\mathrm{M}-81 \mathrm{E}$ and six were in Roma.

To further elucidate how the DELs confer salt tolerance to sweet sorghum, we performed GO annotation analysis on the genes regulated by the 13 IncRNAs (Fig. 3). In the Biological Process domain, besides the term "transcriptional regulation" in $\mathrm{M}-81 \mathrm{E}$, the protein-encoding genes were enriched in terms such as "redox process" and "defense reaction", while in Roma, the terms "defense reaction" and "protein phosphorylation" were enriched. In the Cellular Component domain, besides term the "nucleus", "cytoplasm" was most enriched in M-81E. However, the term "plasma membrane" was most enriched in Roma. In the Molecular Function domain, M-81E was mainly enriched in "protein binding", but Roma was mainly enriched in "ATP binding".

After colocalization and expression analysis using Cytoscape and network construction, we detected five DELs (3 in M-81E and 2 in Roma) from the 13 IncRNAs that might be related with salt responses. The five DELs (IncRNA13472, IncRNA 11310, IncRNA2846, IncRNA26929 and IncRNA14798) were identified as modulators of miRNA that regulated five miRNAs and 14 target genes (Fig. 4a, b). IncRNA13472 might compete with SORBI-3010G218400 for binding to sbi-MIR169b-p3. IncRNA11310 might compete with SORBI-3001G158100, SORBI-3001G223100, SORBI-3002G237000, SORBI-3002G302000, SORBI3003 G327000 and SORBI-3009G182800 for binding to sbi-MIR5567-p3-2ss16CT17TC. IncRNA2846 might compete with SORBI-3001G158100, SORBI-3001G223100, SORBI-3002G237000, SORBI3002G302000, SORBI-3003G327000, SORBI-3004G116300, SORBI-3004G302400, SORBI3006G123500, SORBI-3007G046900, SORBI-3009G182800, SORBI-3009G208000 and SORBI3010G081800 for binding to sbi-MIR5567-p5-2. IncRNA26929 might compete with SORBI3003G327000, SORBI-3001G158100, SORBI-3001G223100 for binding to sbi-MIR5567-p52ss17CT18TC. Finally, IncRNA14798 might compete with SORBI-3009G042700 for binding to PC-3p270284- 34. The expression levels of the five DELs were different in M-81E and Roma. IncRNA13472 was up-regulated in both $\mathrm{M}-81 \mathrm{E}$ and Roma, but its expression level was higher in $\mathrm{M}-81 \mathrm{E}$ than in Roma. However, the expression of IncRNA11310, IncRNA2846 and IncRNA26929 was increased in M-81E and 
decreased in Roma. The expression level of IncRNA14798 was not changed in M-81E and decreased in Roma (Fig. 4c).

To demonstrate that the ceRNA network is involved in the potential regulation of salt tolerance in sweet sorghum roots, we performed a functional enrichment analysis of the 14 target proteins based on GO annotations. It is worth noting that these protein-coding genes were mainly enriched in stress-related terms such as "regulation of transcription", "response to salt stress", "nucleus", "protein binding" and "transport activity" (Fig. 5). These results indicate that under salt stress, IncRNAs can act as ceRNAs and compete with miRNAs for mRNA binding, and may regulate the metabolism of several protein-coding genes involved in important biological processes.

\section{qRT-PCR validation of differentially expressed transcripts from RNA-seq}

To verify the putative relationships between the five DELs, five miRNAs and 14 DEGs, their expression levels were examined by qRT-PCR. The results were consistent with the RNA-seq data, indicating that our RNA-seq results were authentic (Fig. 6).

\section{Discussion}

Salt stress induces ion toxicity, osmotic stress and oxidative stress, which can affect plant physiological metabolism and growth $[5,35]$. To survive under salt stress, plants can regulate their salt tolerance by responding to and adapting to high salt habitats at the transcriptional and post-transcriptional levels [36-39]. Regulation at the transcriptional level is mainly achieved through transcription factors, DNA methylation, histone modification and other processes to activate or inhibit gene-specific expression[40]. At the post-transcriptional level, regulation is mainly achieved by RNA alternative splicing, RNA methylation and multiple RNA-RNA interactions [41-43]. Nonetheless, at present, there is limited detailed information on the functions and regulatory mechanisms of IncRNA, and how it plays a role in the regulation of salt stress in sweet sorghum is still little known.

In recent years, many studies have shown that IncRNA can be used to characterize the regulation of physiological metabolism and growth and development because it regulates the modification of histones, nucleic acid structure modification, nucleic acid methylation and RNA-RNA interactions [44, 45]. IncRNAs are actively involved in the salt stress response in cotton, which was confirmed by Deng et al. [14]. However, their study was focused on cis-acting regulation in which IncRNAs act as ubiquitous regulators. Moreover, Wang et al. [46] observed that there were differences in the number of IncRNAs in the roots and leaves of Medicago truncatula under salt stress. The number of IncRNAs in the roots was much larger than in leaves, which seems to indicate IncRNAs are especially active in plant roots. In this study, we selected the salt-tolerant genotype $\mathrm{M}-81 \mathrm{E}$ and salt-sensitive genotype Roma as experimental materials to explore how IncRNA acts as ceRNA to actively respond to salt stress in sweet sorghum roots. 
To investigate this problem, we performed RNA-seq on $\mathrm{M}-81 \mathrm{E}$ and Roma roots after $\mathrm{NaCl}$ treatment. After annotating, characterizing and analyzing the RNA-seq data, our transcriptome profiling results were similar to previous results [47]. The DEGs of the different inbred lines were mainly enriched in transcription factors, transport proteins, antioxidants and proton pumps. We predicted the ceRNA relationships of the DELs using StarBase, and identified 477 and 195 IncRNA-miRNA-mRNA relationships in $\mathrm{M}-81 \mathrm{E}$ and Roma, respectively (Fig. S2). Many more interactions were found in M-81E than in Roma, which suggests that $\mathrm{M}-81 \mathrm{E}$ has a more accurate and complex ceRNA regulation mechanism for the response to salt stress, which may be one of the reasons that $\mathrm{M}-81 \mathrm{E}$ is more tolerant to salt stress.

Furthermore, we selected five IncRNAs that were related to salt stress for in-depth study. Their expression levels were different in the two lines under salt stress. Among them, IncRNA13472 was up-regulated in both M-81E and Roma, but had higher expression in M-81E than in Roma. IncRNA11310, IncRNA2846 and IncRNA26929 were up-regulated in M-81E and down-regulated in Roma. The expression level of IncRNA14798 decreased in Roma and did not change in M-81E (Fig. 4c). These IncRNAs were predicted to compete with 14 DEGs for binding to five miRNAs (Fig. 4a, b).

To clarify how ceRNAs participate in the response to salt stress, we further analyzed the IncRNA-miRNAmRNA relationships and the roles of the 14 DEGs. The DEGs mainly encoded proton pumps, transport proteins, certain important enzymes and transcription factors (Table S2). Similarly, miRNAs target many transcription factors, signaling factors, and transporter-encoding genes, which have been shown to be involved in response to salt stress [48]. Interestingly, miRNAs also play an important role in the ceRNA network. Among them, sbi-MIR169b can be down-regulated under drought stress [49]. However, its expression level was up-regulated in our transcriptome profile. In this study, SORBI-3010G218400 was predicted to bind sbi-MIR169b in competition with IncRNA13472. SORBI-3010G218400 encodes V-type proton ATPase catalytic subunit A (VHA-A). V-ATPase (VHA) is an ATP-dependent proton pump located on the eukaryotic plasma membrane that is involved in the transmembrane transport of protons and in responses to salt stress [50-54]. The A subunit is an important component of VHA. Here, the expression level of SORBI-3010G218400 increased, which might be helpful for establishing a transmembrane proton gradient. Coincidentally, sbi-MIR5567 was detected as a sorghum-specific miRNA [55], but how sbi-MIR5567-p3-2ss16CT17TC, sbi-MIR5567-p5-2 and sbi-MIR5567-p5-2ss17CT18TC participate in the complex ceRNA regulatory networks and the response to salt stress is unknown. The target genes of sbiMIR5567-p3-2ss16CT17TC are SORBI-3001G158100, SORBI-3001G223100, SORBI-3002G237000, SORBI-3002G302000, SORBI-3003G327000, and SORBI-3009G182800.They can compete with IncRNA11310 for binding to sbi-MIR5567-p3-2ss16CT17TC. SORBI-3001G158100 encodes BTB/POZ and MATH domain-containing protein 1 (BPM1). Members of the BPM family act as regulators of ABA responses and play important roles in plant development and stress responses. In the cytoplasm, BPM1 binds to CUL3 E3 ubiquitin ligase to degrade the 26S proteasome. However, in the nucleus, it can bind to transcription factors to regulate transcription. Moreover, studies have shown that reducing the function of BPM affects the opening and closing of stomata and ABA responsiveness, which in turn affects plant development and reproduction [56]. BPM1 was found to be induced by hormones and to enhance the resistance of host plants to pathogenic microorganisms [57] in $A$. thaliana $[58,59]$ and soybeans [60]. 
SORBI-3001G223100 encodes the protein NRT1/PTR FAMILY 5.2 (NPF5.2), a transporter of a variety of substances including nitrates, chlorides and phytohormones $[9,61,62]$, which have been shown to respond to drought stress [63]. SORBI-3002G237000 encodes fasciclin-like arabinogalactan protein 1 (FLA1). FLA1 has been shown to be involved in the salt stress response [64], and plays a crucial role in plant development [65-67]. SORBI-3002G302000 encodes xyloglucan endotransglucosylase/hydrolase protein 31 (XTH31), a cell wall modifying enzyme that is involved in plant cell wall formation in plants such as wheat $[68,69]$, regulates root hair development in $A$. thaliana $[70,71]$, and responds to drought stress in maize [72]. SORBI-3003G327000 and SORBI-3009G182800 both encode basic leucine zipper 23 (bZIP23). bZIP proteins in Arabidopsis are involved in drought and high salinity responses and the ABA-dependent signal transduction pathway $[73,74]$. Except for FLA1, the expression levels of the above five genes regulated by sbi-MIR5567-p3-2ss16CT17TC were increased under salt stress. These six genes encode ion transporters, cell wall modifying enzymes, and transcription factors. Thus, we speculate that IncRNA1310 confers high salt tolerance to plants by binding with sbi-MIR5567-p3-2ss16CT17TC and reducing the degradation of these target genes. SORBI-3001G158100, SORBI-3001G223100, SORBI3002G237000, SORBI-3002G302000, SORBI-3003G327000, SORBI-3004G116300, SORBI3004G302400, SORBI-3006G123500, SORBI-3007G046900, SORBI-3009G182800, SORBI3009 G208000 and SORBI-3010G081800 may compete with IncRNA2846 for binding to sbi-MIR5567p5-2. SORBI-3001G158100 and SORBI-3007G046900 encode BPM1, SORBI-3001G223100 encodes NPF5.2, SORBI-3002G237000 encodes FLA1, SORBI-3002G302000 encodes XTH31, and SORBI$3003 G 327000$ and SORBI-3009G182800 both encode bZIP23. SORBI-3004G116300 encodes BCl-2associated athanogene (BAG6).BAG6 selectively promotes mislocalized proteasomal degradation by ubiquitination [75]. Moreover, Kang et al. [76] confirmed that AtBAG6 is a stress-regulated calmodulinbinding protein associated with programmed cell death in plants. Studies have shown that loss of BAG6 leads to reduced resistance to the fungal phytopathogen Botrytis cinerea [77]. SORBI-3004G302400 and SORBI-3010G081800 encode NAC domain-containing protein 7 (NAC007) and bZIP transcription factor 23 (bZIP TF 23), respectively. These proteins serve as two important transcription factors that regulate the expression of target genes at the transcriptional level to improve plant disease resistance [78] and can improve the salt tolerance and drought resistance of plants such as Arabidopsis, rice, corn and tomato [79-83]. SORBI-3006G123500 is an important antioxidant gene $[84,85]$ that encodes the peptide methionine sulfoxide reductase A2-1 (MSRA2-1). MSRA2-1 participates in oxidative stress, is induced by salt stress in plants, and increases the salt tolerance of plants. As molecular chaperones, heat shock proteins (HSPs) help to maintain the structural integrity of cells and normal processes of cellular metabolism by assisting in the correct folding of proteins [86]. Fragkostefanakis et al. believe that heat stress transcription factors (Hsfs) interact with HSPs to confer plants the ability to resist stress [87]. The Hsf A-4d (HSFA4D) is an important transcription factor with transcriptional activator function that is encoded by SORBI-3009G208000. Hsfs in plants are not only related to heat stress, but also play an important role in responses to drought, oxidation, and biological stress [88-91]. In this study, the expression of most genes was up-regulated. We predict that SORBI-3003G327000, SORBI$3001 G 158100$ and SORBI-3001G223100 may compete with InCRNA26929 to bind sbi-MIR5567-p52ss17CT18TC. As mentioned above, SORBI-3003G327000 encodes bZIP23, SORBI-3001G158100 
encodes BPM1 and SORBI-3001G223100 encodes NPF5.2. Interestingly, in this set of predicted target relationships, the expression levels of SORBI-3003G327000 and SORBI-3001G158100 increased, but the expression of SORBI-3001G223100 was down-regulated. PC-3p has been shown to regulate plant development [92], but it is not known how PC-3p-270284-34 regulates plant responses to salt stress. SORBI-3009G042700, which can bind to PC-3p-270284-34 in competition with IncRNA14798, encodes sodium/hydrogen exchanger 2-like ( $\mathrm{NHX} 2)$, a Na${ }^{+}, \mathrm{K}^{+} / \mathrm{H}^{+}$antiporter mainly located on the tonoplast membrane. As an ion homeostasis transporter, it regulates intracellular ion homeostasis and reduces ionic toxicity in plants due to salt stress [93]. Barragán et al. showed that the NHX2 protein confers stress tolerance by participating in the regulation of $\mathrm{K}^{+}$homeostasis, intracellular $\mathrm{pH}$, and stomatal opening and closing [94].

\section{Conclusion}

In conclusion, our results revealed five unknown IncRNAs in M-81E and Roma under salt stress. These DELs act as ceRNAs that affect the salt tolerance of plants by regulating the transcription levels of certain proton pumps, transporters, important enzymes and transcription factors. These ceRNAs are highly correlated with the salt tolerance of sweet sorghum, and can therefore help to explain the mechanism of salt stress tolerance in plants and discover new genes that regulate plant salt tolerance.

\section{Abbreviations}

BAG6: Bcl-2-associated athanogene

BPM1: BTB/POZ and MATH domain-containing protein 1

bZIP TF 23: bZIP transcription factor 23

bZIP23: basic leucine zipper 23

ceRNAs: competitive endogenous RNAs

DEGs: differentially expressed genes

DELs: differentially expressed IncRNAs

FLA1: fasciclin-like arabinogalactan protein 1

FPKM: Fragments Per Kilobase of exon model per Million mapped fragments

GO: Gene ontology

HSFA4D: Hsf A-4d

Hsfs: heat stress transcription factors 
HSPs: heat shock proteins

IncRNA: long non-coding RNAs

MicroRNA: miRNA

MIRISCs: miRNA-mediated silencing complexes

MREs: miRNA response elements

MSRA2-1: methionine sulfoxide reductase A2-1

NAC007: NAC domain-containing protein 7

NHX2: sodium/hydrogen exchanger 2-like

NPF5.2: NRT1/PTR FAMILY 5.2

RNA-seq: high-throughput Illumina RNA sequencing

sncRNA: small non-coding RNAs

VHA-A: V-type proton ATPase catalytic subunit A

XTH31: xyloglucan endotransglucosylase/hydrolase protein 31

\section{Declarations}

\section{Ethics approval and consent to participate}

Not applicable.

\section{Consent to publish}

Not applicable.

\section{Competing interests}

No competing interests.

\section{Availability of data and materials}


The datasets used and/or analysed during the current study are available from the corresponding author on reasonable request.

\section{Funding}

We are grateful for financial support from the National Key R\&D Program of China (2018YFD1000700, 2018YFD1000704), the National Natural Science Research Foundation of China (31871538), the Opening Foundation of Shandong Provincial Key Laboratory of Crop Genetic Improvement, Ecology and Physiology (SDKL2018008-3). These funding bodies did not play any roles in the design of the study and collection, analysis, and interpretation of data and in writing the manuscript.

\section{Authors' Contributions}

$\mathrm{XS}, \mathrm{HZ}$ and $\mathrm{JL}$ imitated the manuscript. XS and HZ performed experiments; XS and NS collected data and carried out all analyses; NS conceptualized the idea and revised the manuscript. All authors read and approved the final manuscript.

\section{Acknowledgements}

Not applicable.

\section{References}

1.Feng Z, Deng Y, Fan H, Sun Q, Sui N, Wang B: Effects of NaCl stress on the growth and photosynthetic characteristics of Ulmus pumila L. seedlings in sand culture. Photosynthetica 2014, 52(2):313-320.

2.Sui N, Han G: Salt-induced photoinhibition of PSII is alleviated in halophyte Thellungiella halophila by increases of unsaturated fatty acids in membrane lipids. Acta physiologiae plantarum 2014, 36(4):983992.

3.Cui F, Sui N, Duan G, Liu Y, Han Y, Liu S, Wan S, Li G: Identification of metabolites and transcripts involved in salt stress and recovery in peanut. Frontiers in plant science 2018, 9.217.

4.Yang Z, Wang Y, Wei X, Zhao X, Wang B, Sui N: Transcription profiles of genes related to hormonal regulations under salt stress in sweet sorghum. Plant molecular biology reporter 2017, 35(6):586-599.

5.Kumar V, Khare T, Shriram V, Wani SH: Plant small RNAs: the essential epigenetic regulators of gene expression for salt-stress responses and tolerance. Plant Cell Reports 2018, 37(735-744):1-15.

6.Sun X, Xu L, Wang Y, Yu R, Zhu X, Luo X, Gong Y, Wang R, Limera C, Zhang K: Identification of novel and salt-responsive miRNAs to explore miRNA-mediated regulatory network of salt stress response in radish( 
Raphanus sativus L.). BMC Genomics,16,1(2015-03-17) 2015, 16(1):197.

7.Mondal TK, Panda AK, Rawal HC, Sharma TR: Discovery of microRNA-target modules of African rice ( Oryza glaberrima) under salinity stress. Sci Rep 2018, 8(1):570.

8.Zhang YC, Chen YQ: Long noncoding RNAs: New regulators in plant development. Biochemical \& Biophysical Research Communications 2013, 436(2):111-114.

9.al. HPCXDQe: Identification and characterization of wheat long non-protein coding RNAs responsive to powdery mildew infection and heat stress by using microarray analysis and SBS sequencing. BMC Plant Biology 2011, 11(1):61.

10.Seitz H: Redefining microRNA targets. Current Biology Cb 2009, 19(10):870-873.

11.Eric H: Gene silencing by microRNAs: contributions of translational repression and mRNA decay. Nature Reviews Genetics 2011, 12(2):99-110.

12.Mercer TR, Dinger ME, Mattick JS: Long non-coding RNAs: insights into functions. Nature Reviews Genetics 2009, 10(3):155-159.

13.Yvonne T, John R, Pier Paolo P: The multilayered complexity of ceRNA crosstalk and competition. Nature 2014, 505(7483):344-352.

14.Deng F, Zhang X, Wang W, Yuan R, Shen F: Identification of Gossypium hirsutum long non-coding RNAs (IncRNAs) under salt stress. BMC plant biology 2018, 18(1):23.

15. Huanca-Mamani W, Arias-Carrasco R, Cárdenas-Ninasivincha S, Rojas-Herrera M, SepúlvedaHermosilla G, Caris-Maldonado J, Bastías E, Maracaja-Coutinho V: Long non-coding RNAs responsive to salt and boron stress in the hyper-arid Lluteno maize from Atacama Desert. Genes 2018, 9(3):170.

16.Gai YP, Yuan SS, Zhao YN, Zhao HN, Zhang HL, Ji XL: A novel LncRNA, MuLnc1, associated with environmental stress in Mulberry (Morus multicaulis). Frontiers in plant science 2018, 9.

17.Amor BB, Wirth S, Merchan F, Laporte P, d'Aubenton-Carafa Y, Hirsch J, Maizel A, Mallory A, Lucas A, Deragon JM: Novel long non-protein coding RNAs involved in Arabidopsis differentiation and stress responses. Genome research 2009, 19(1):57-69.

18.Swiezewski S, Liu F, Magusin A, Dean C: Cold-induced silencing by long antisense transcripts of an Arabidopsis Polycomb target. Nature 2009, 462(7274):799.

19.Heo JB, Sung S: Vernalization-mediated epigenetic silencing by a long intronic noncoding RNA. Science 2011, 331(6013):76-79.

20.Li L, Eichten SR, Shimizu R, Petsch K, Yeh CT, Wu W, Chettoor AM, Givan SA, Cole RA, Fowler JE: Genome-wide discovery and characterization of maize long non-coding RNAs. Genome biology 2014, 
15(2):R40.

21.Guo YY, Tian SS, Liu SS, Wang WQ, Sui N: Energy dissipation and antioxidant enzyme system protect photosystem II of sweet sorghum under drought stress. Photosynthetica 2018, 56(3):861-872.

22.Sui N, Yang Z, Liu M, Wang B: Identification and transcriptomic profiling of genes involved in increasing sugar content during salt stress in sweet sorghum leaves. BMC Genomics,16,1(2015-07-19) 2015, 16:534.

23.Zhen Y; Hongxiang Z; Xiaocen W; Jie SB, W; Na, S: Transcriptome analysis of sweet Sorghum inbred lines differing in salt tolerance provides novel insights into salt exclusion by roots. Plant and Soil 2018, 430(1-2):423-439.

24.Pertea M, Pertea GM, Antonescu CM, Chang TC, Mendell JT, Salzberg SL: StringTie enables improved reconstruction of a transcriptome from RNA-seq reads. Nature biotechnology 2015, 33(3):290.

25.Langmead B, Salzberg SL: Fast gapped-read alignment with Bowtie 2. Nature methods 2012, 9(4):357.

26.Kim D, Pertea G, Trapnell C, Pimentel H, Kelley R, Salzberg SL: TopHat2: accurate alignment of transcriptomes in the presence of insertions, deletions and gene fusions. Genome biology 2013, 14(4):R36.

27.Kong L, Zhang Y, Ye ZQ, Liu XQ, Zhao SQ, Wei L, Gao G: CPC: assess the protein-coding potential of transcripts using sequence features and support vector machine. Nucleic acids research 2007, 35(suppl_2):W345-W349.

28.Finn R, Mistry J, Tate J, Coggill P, Heger A, Pollington J, Gavin O, Gunesekaran P, Ceric G, Forslund K: The Pfam protein families database: Nucleic Acids Research Database Issue 38: D211-222. In.; 2010.

29.Frazee AC, Pertea G, Jaffe AE, Langmead B, Salzberg SL, Leek JT: Ballgown bridges the gap between transcriptome assembly and expression analysis. Nature biotechnology 2015, 33(3):243.

30.Ewing B, Hillier L, Wendl MC, Green P: Base-calling of automated sequencer traces usingPhred. I. Accuracy assessment. Genome research 1998, 8(3):175-185.

31.Zhang J, Wei L, Jiang J, Mason AS, Li H, Cui C, Chai L, Zheng B, Zhu Y, Xia Q: Genome-wide identification, putative functionality and interactions between IncRNAs and miRNAs in Brassica species. Scientific reports 2018, 8(1):4960.

32.He X, Guo S, Wang Y, Wang L, Shu S, Sun J: Systematic identification and analysis of heat-stressresponsive IncRNAs, circRNAs and miRNAs with associated co-expression and ceRNA networks in cucumber (Cucumis sativus L.). Physiologia plantarum 2019. 
33.Wu HJ, Wang ZM, Wang M, Wang XJ: Widespread long noncoding RNAs as endogenous target mimics for microRNAs in plants. Plant physiology 2013, 161(4):1875-1884.

34.Meng X, Zhang P, Chen Q, Wang J, Chen M: Identification and characterization of ncRNA-associated ceRNA networks in Arabidopsis leaf development. BMC genomics 2018, 19(1):607.

35.Liang W, Ma X, Wan P, Liu L: Plant salt-tolerance mechanism: A review. Biochemical and biophysical research communications 2018, 495(1):286-291.

36.Shinozaki K, Yamaguchi-Shinozaki K, Seki M: Regulatory network of gene expression in the drought and cold stress responses. Current opinion in plant biology 2003, 6(5):410-417.

37.Feller A, Machemer K, Braun EL, Grotewold E: Evolutionary and comparative analysis of MYB and bHLH plant transcription factors. The Plant Journal 2011, 66(1):94-116.

38.Law JA, Jacobsen SE: Establishing, maintaining and modifying DNA methylation patterns in plants and animals. Nature Reviews Genetics 2010, 11(3):204.

39.Tariq M, Paszkowski J: DNA and histone methylation in plants. TRENDS in Genetics 2004, 20(6):244251.

40.Zhang Y, Li X, Goodrich J, Wu C, Wei H, Yang S, Feng X: Reduced function of the RNA-binding protein FPA rescues a T-DNA insertion mutant in the Arabidopsis ZHOUPI gene by promoting transcriptional readthrough. Plant molecular biology 2016, 91(4-5):549-561.

41.Bardou F, Ariel F, Simpson CG, Romero-Barrios N, Laporte P, Balzergue S, Brown JW, Crespi M: Long noncoding RNA modulates alternative splicing regulators in Arabidopsis. Developmental cell 2014, 30(2):166-176.

42.Wassenegger $\mathrm{M}$, Heimes $\mathrm{S}$, Riedel $\mathrm{L}$, Sänger $\mathrm{HL}$ : RNA-directed de novo methylation of genomic sequences in plants. Cell 1994, 76(3):567-576.

43.Zhu J, Dong $\mathrm{CH}$, Zhu JK: Interplay between cold-responsive gene regulation, metabolism and RNA processing during plant cold acclimation. Current opinion in plant biology 2007, 10(3):290-295.

44.Qin T, Xiong L: Subcellular Localization and Functions of Plant IncRNAs in Drought and Salt Stress Tolerance. In: Plant Long Non-Coding RNAs. Springer; 2019: 173-186.

45.Matsui A, Seki M: The Involvement of Long Noncoding RNAs in Response to Plant Stress. In: Plant Long Non-Coding RNAs. Springer; 2019: 151-171.

46.Wang T, Liu M, Zhao MG, Chen R, Zhang WH: Identification and characterization of long non-coding RNAs involved in osmotic and salt stress in Medicago truncatula using genome-wide high-throughput sequencing. BMC plant biology 2015, 15(1):131. 
47.Yang Z, Zheng H, Wei X, Song J, Wang B, Sui N: Transcriptome analysis of sweet Sorghum inbred lines differing in salt tolerance provides novel insights into salt exclusion by roots. Plant and Soil 2018, 430(12):423-439.

48.Zhang Q, Zhao C, Li M, Sun W, Zhao Y: Genome-wide identification of Thellungiella salsuginea microRNAs with putative roles in the salt stress response. BMC Plant Biology,13,1(2013-11-15) 2013, 13(1):180.

49.Maor R: MicroRNA compositions and methods for enhancing plant resistance to abiotic stress. In.: Google Patents; 2017.

50.Forgac M: Structure, function and regulation of the vacuolar (H+)-ATPases. FEBS letters 1998, 440(3):258-263.

51.Boekema E, Van Breemen J, Brisson A, Ubbink-Kok T, Konings W, Lolkema J: Biological motors: Connecting stalks in V-type ATPase. Nature 1999, 401(6748):37.

52.Powell B, Graham LA, Stevens TH: Molecular characterization of the yeast vacuolar H+-ATPase proton pore. Journal of Biological Chemistry 2000, 275(31):23654-23660.

53.Toei M, Toei S, Forgac M: Definition of membrane topology and identification of residues important for transport in subunit a of the vacuolar ATPase. Journal of Biological Chemistry 2011, 286(40):3517635186.

54.Vera-Estrella R, Barkla BJ, García-Ramírez L, Pantoja O: Salt stress in Thellungiella halophila activates $\mathrm{Na}+$ transport mechanisms required for salinity tolerance. Plant Physiology 2005, 139(3):1507-1517.

55.Zhang L, Zheng Y, Jagadeeswaran G, Li Y, Gowdu K, Sunkar R: Identification and temporal expression analysis of conserved and novel microRNAs in Sorghum. Genomics 2011, 98(6):460-468.

56.Chen L, Lee JH, Weber H, Tohge T, Witt S, Roje S, Fernie AR, Hellmann H: Arabidopsis BPM proteins function as substrate adaptors to a cullin3-based E3 ligase to affect fatty acid metabolism in plants. The Plant Cell 2013, 25(6):2253-2264.

57.Zhang Y, Fan W, Kinkema M, Li X, Dong X: Interaction of NPR1 with basic leucine zipper protein transcription factors that bind sequences required for salicylic acid induction of the $P R-1$ gene. Proceedings of the National Academy of Sciences 1999, 96(11):6523-6528.

58.Cao H, Glazebrook J, Clarke JD, Volko S, Dong X: The Arabidopsis NPR1 gene that controls systemic acquired resistance encodes a novel protein containing ankyrin repeats. Cell 1997, 88(1):57-63.

59.Delaney T, Friedrich L, Ryals J: Arabidopsis signal transduction mutant defective in chemically and biologically induced disease resistance. Proceedings of the National Academy of Sciences 1995, 92(14):6602-6606. 
60.Zhang C, Gao H, Li R, Han D, Wang L, Wu J, Xu P, Zhang S: GmBTB/POZ, a novel BTB/POZ domaincontaining nuclear protein, positively regulates the response of soybean to Phytophthora sojae infection. Molecular plant pathology 2019, 20(1):78-91.

61.Corratgé-Faillie C, Lacombe B: Substrate (un) specificity of Arabidopsis NRT1/PTR FAMILY (NPF) proteins. Journal of experimental botany 2017, 68(12):3107-3113.

62.Chiba Y, Shimizu T, Miyakawa S, Kanno Y, Koshiba T, Kamiya Y, Seo M: Identification of Arabidopsis thaliana NRT1/PTR FAMILY (NPF) proteins capable of transporting plant hormones. Journal of plant research 2015, 128(4):679-686.

63.Parmar R, Seth R, Singh P, Singh G, Kumar S, Sharma RK: Transcriptional profiling of contrasting genotypes revealed key candidates and nucleotide variations for drought dissection in Camellia sinensis (L.) O. Kuntze. Scientific reports 2019, 9(1):7487.

64.Shi H, Kim Y, Guo Y, Stevenson B, Zhu JK: The Arabidopsis SOS5 locus encodes a putative cell surface adhesion protein and is required for normal cell expansion. The Plant Cell2003, 15(1):19-32.

65.Johnson KL, Jones BJ, Bacic A, Schultz CJ: The fasciclin-like arabinogalactan proteins of Arabidopsis. A multigene family of putative cell adhesion molecules. Plant physiology 2003, 133(4):1911-1925.

66.Lafarguette F, Leplé JC, Déjardin A, Laurans F, Costa G, Lesage-Descauses MC, Pilate G: Poplar genes encoding fasciclin-like arabinogalactan proteins are highly expressed in tension wood. New Phytologist 2004, 164(1):107-121.

67.Brown DM, Zeef LA, Ellis J, Goodacre R, Turner SR: Identification of novel genes in Arabidopsis involved in secondary cell wall formation using expression profiling and reverse genetics. The Plant Cell 2005, 17(8):2281-2295.

68.Saladié M, Rose JK, Cosgrove DJ, Catalá C: Characterization of a new xyloglucan endotransglucosylase/hydrolase (XTH) from ripening tomato fruit and implications for the diverse modes of enzymic action. The Plant Journal 2006, 47(2):282-295.

69.Liu Y, Liu D, Zhang H, Gao H, Guo X, Wang D, Zhang X, Zhang A: The a-and $\beta$-expansin and xyloglucan endotransglucosylase/hydrolase gene families of wheat: Molecular cloning, gene expression, and EST data mining. Genomics 2007, 90(4):516-529.

70.Cho HT, Cosgrove DJ: Regulation of root hair initiation and expansin gene expression in Arabidopsis. The Plant Cell 2002, 14(12):3237-3253.

71.Vissenberg K, Fry SC, Verbelen JP: Root hair initiation is coupled to a highly localized increase of xyloglucan endotransglycosylase action in Arabidopsis roots. Plant Physiology 2001, 127(3):1125-1135. 
72.Wu Y, Thorne ET, Sharp RE, Cosgrove DJ: Modification of expansin transcript levels in the maize primary root at low water potentials. Plant Physiology 2001, 126(4):1471-1479.

73.Uno Y, Furihata T, Abe H, Yoshida R, Shinozaki K, Yamaguchi-Shinozaki K: Arabidopsis basic leucine zipper transcription factors involved in an abscisic acid-dependent signal transduction pathway under drought and high-salinity conditions. Proceedings of the National Academy of Sciences 2000, 97(21):11632-11637.

74.Kang Jy, Choi Hi, Im My, Kim SY: Arabidopsis basic leucine zipper proteins that mediate stressresponsive abscisic acid signaling. The Plant Cell 2002, 14(2):343-357.

75.Leznicki P, High S: SGTA antagonizes BAG6-mediated protein triage. Proceedings of the National Academy of Sciences 2012, 109(47):19214-19219.

76.Kang CH, Jung W, Kang Y, Kim J, Kim D, Jeong J, Baek D, Jin J, Lee J, Kim M: AtBAG6, a novel calmodulin-binding protein, induces programmed cell death in yeast and plants. Cell death and differentiation 2006, 13(1):84.

77.Li Y, Kabbage M, Liu W, Dickman MB: Aspartyl protease-mediated cleavage of BAG6 is necessary for autophagy and fungal resistance in plants. The Plant Cell 2016, 28(1):233-247.

78.Aida M, Ishida T, Fukaki H, Fujisawa H, Tasaka M: Genes involved in organ separation in Arabidopsis: an analysis of the cup-shaped cotyledon mutant. The Plant Cell 1997, 9(6):841-857.

79.Hu H, Dai M, Yao J, Xiao B, Li X, Zhang Q, Xiong L: Overexpressing a NAM, ATAF, and CUC (NAC) transcription factor enhances drought resistance and salt tolerance in rice. Proceedings of the National Academy of Sciences 2006, 103(35):12987-12992.

80.Tran LSP, Nakashima K, Sakuma Y, Simpson SD, Fujita Y, Maruyama K, Fujita M, Seki M, Shinozaki K, Yamaguchi-Shinozaki K: Isolation and functional analysis of Arabidopsis stress-inducible NAC transcription factors that bind to a drought-responsive cis-element in the early responsive to dehydration stress 1 promoter. The Plant Cel/2004, 16(9):2481-2498.

81.Xu Z: Characterization of endogenous transposon families and transposon tagged mutations in maize. Rutgers The State University of New Jersey-New Brunswick; 2005.

82.Jakoby M, Weisshaar B, Dröge-Laser W, Vicente-Carbajosa J, Tiedemann J, Kroj T, Parcy F: bZIP transcription factors in Arabidopsis. Trends in plant science 2002, 7(3):106-111.

83.Hsieh TH, Li CW, Su RC, Cheng CP, Tsai YC, Chan MT: A tomato bZIP transcription factor, SIAREB, is involved in water deficit and salt stress response. Planta 2010, 231(6):1459-1473.

84.Moskovitz J, Berlett BS, Poston JM, Stadtman ER: The yeast peptide-methionine sulfoxide reductase functions as an antioxidant in vivo. Proceedings of the National Academy of Sciences 1997, 
94(18):9585-9589.

85.Oh JE, Hong SW, Lee Y, Koh EJ, Kim K, Seo YW, Chung N, Jeong M, Jang CS, Lee B: Modulation of gene expressions and enzyme activities of methionine sulfoxide reductases by cold, ABA or high salt treatments in Arabidopsis. Plant Science 2005, 169(6):1030-1036.

86.Sung DY, Guy CL: Physiological and molecular assessment of altered expression of Hsc70-1 in Arabidopsis. Evidence for pleiotropic consequences. Plant Physiology 2003, 132(2):979-987.

87.Fragkostefanakis S, Simm S, El-Shershaby A, Hu Y, Bublak D, Mesihovic A, Darm K, Mishra SK, Tschiersch B, Theres $\mathrm{K}$ : The repressor and co-activator HsfB1 regulates the major heat stress transcription factors in tomato. Plant, cell \& environment 2019, 42(3):874-890.

88.Scharf KD, Berberich T, Ebersberger I, Nover L: The plant heat stress transcription factor (Hsf) family: structure, function and evolution. Biochimica et Biophysica Acta (BBA)-Gene Regulatory Mechanisms 2012, 1819(2):104-119.

89.Qin F, Kakimoto M, Sakuma Y, Maruyama K, Osakabe Y, Tran LSP, Shinozaki K, Yamaguchi-Shinozaki $\mathrm{K}$ : Regulation and functional analysis of ZmDREB2A in response to drought and heat stresses in Zea mays L. The Plant Journal 2007, 50(1):54-69.

90.Zhang L, Li Y, Xing D, Gao C: Characterization of mitochondrial dynamics and subcellular localization of ROS reveal that HsfA2 alleviates oxidative damage caused by heat stress in Arabidopsis. Journal of experimental botany 2009, 60(7):2073-2091.

91.Kumar M, Busch W, Birke H, Kemmerling B, Nürnberger T, Schöff F: Heat shock factors HsfB1 and $H s f B 2 b$ are involved in the regulation of Pdf1. 2 expression and pathogen resistance in Arabidopsis. Molecular plant 2009, 2(1):152-165.

92.Xu X, Yin L, Ying Q, Song H, Xue D, Lai T, Xu M, Shen B, Wang H, Shi X: High-throughput sequencing and degradome analysis identify miRNAs and their targets involved in fruit senescence of Fragaria ananassa. PLoS One 2013, 8(8):e70959.

93. Ueda M, Sako K, Seki M: Regulation and modification of the epigenome for enhanced salinity tolerance in crop plants. In: Salinity Responses and Tolerance in Plants, Volume 2. Springer; 2018: 77-91.

94.Barragán V, Leidi EO, Andrés Z, Rubio L, De Luca A, Fernández JA, Cubero B, Pardo JM: Ion exchangers NHX1 and NHX2 mediate active potassium uptake into vacuoles to regulate cell turgor and stomatal function in Arabidopsis. The Plant Cell 2012, 24(3):1127-1142.

\section{Figures}


(a)

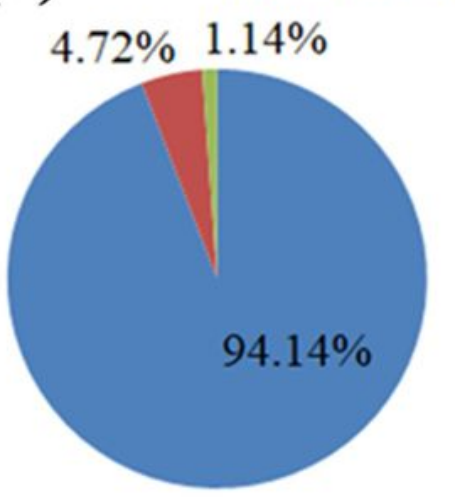

Roma-CK

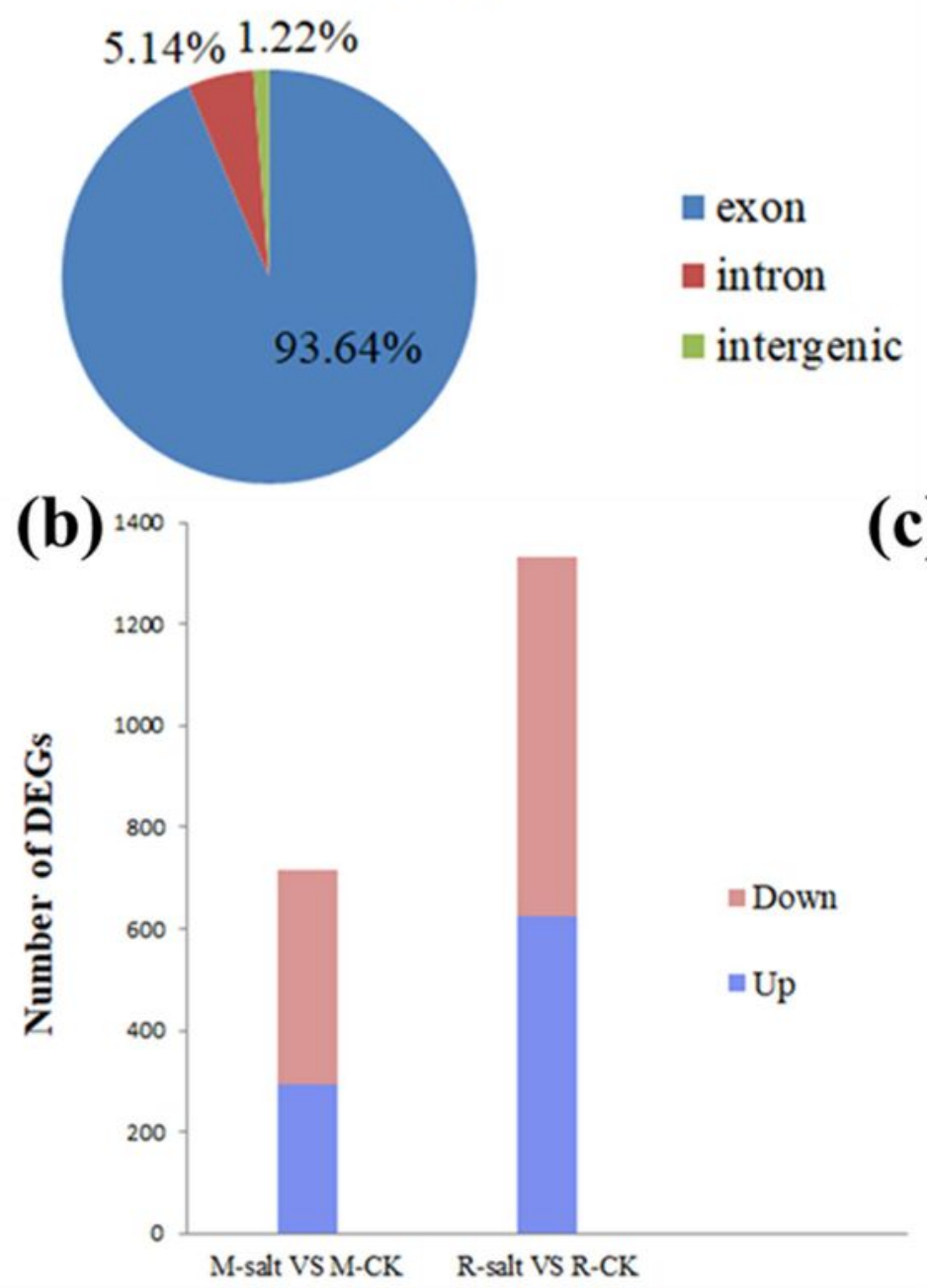

M-81E-salt

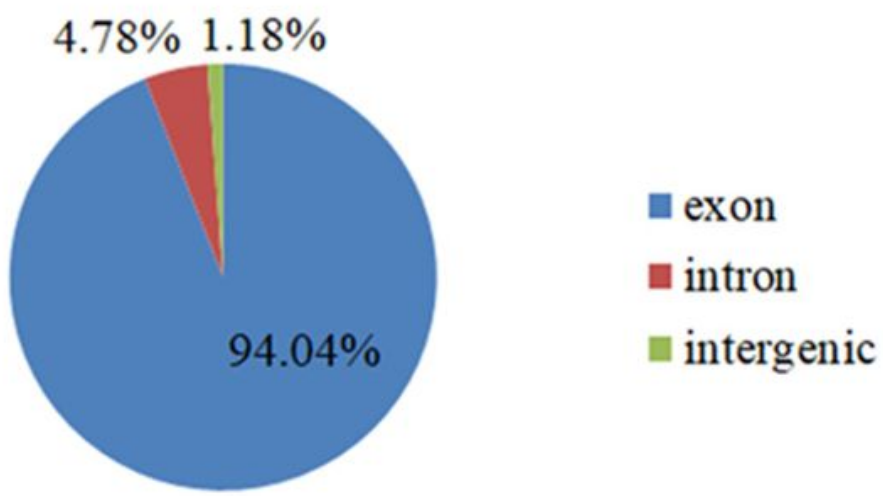

Roma-salt

$4.65 \% \quad 1.25 \%$

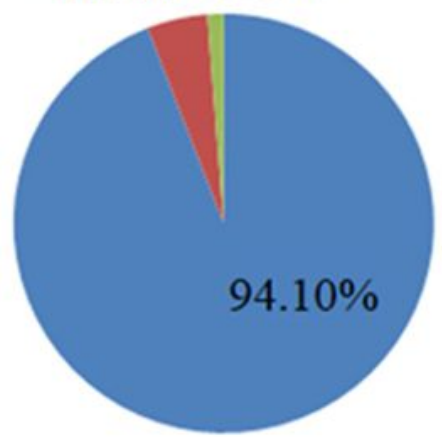

a exon

a intron

nintergenic

(c)

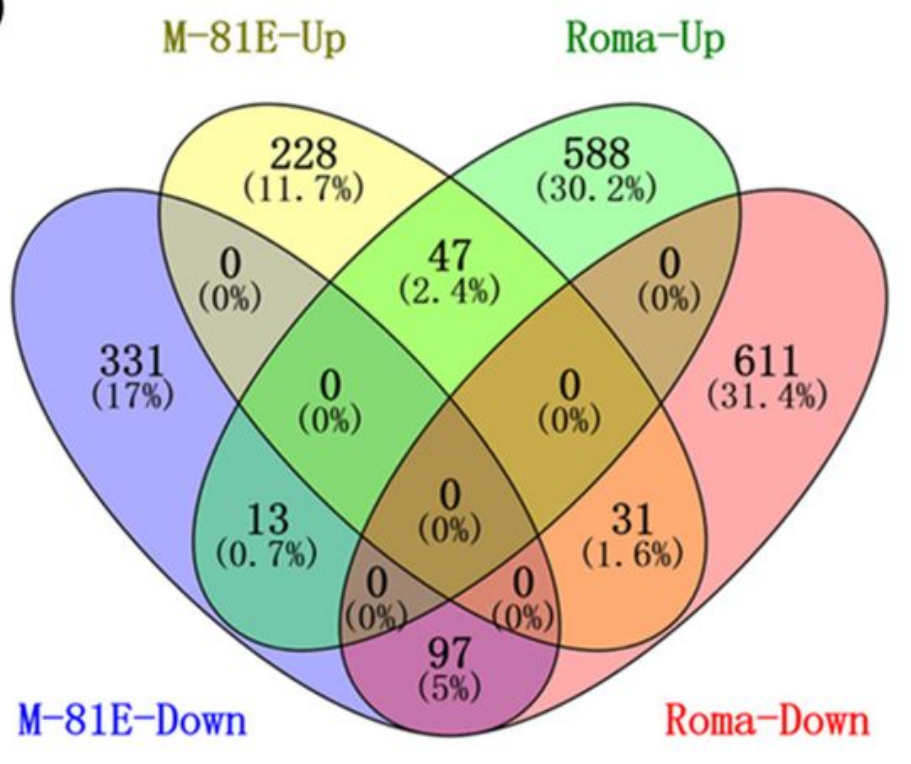

\section{Figure 1}

Unique reads mapped to various genomic regions, and identification and characterization of DEGs in M81E and Roma between salt stress and control samples. (a) Unique reads mapped to various genomic regions. (b) Numbers of DEGs. (c) Venn diagram showing DEGs typically expressed in M-81E and Roma samples. 


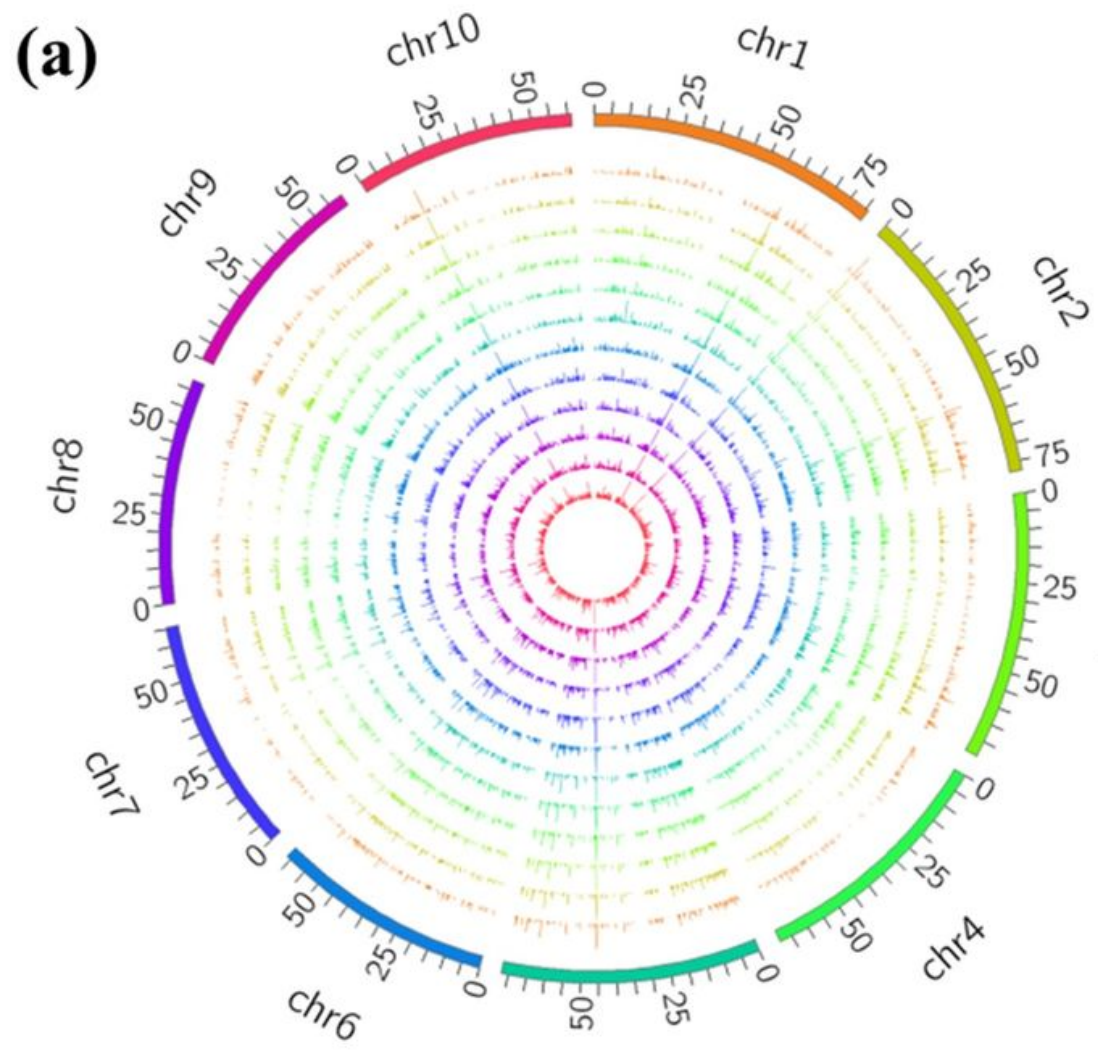

(b) M-81E-salt

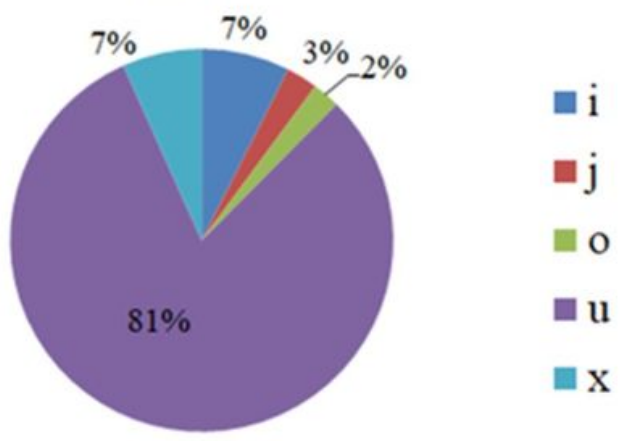

(c)

chr5
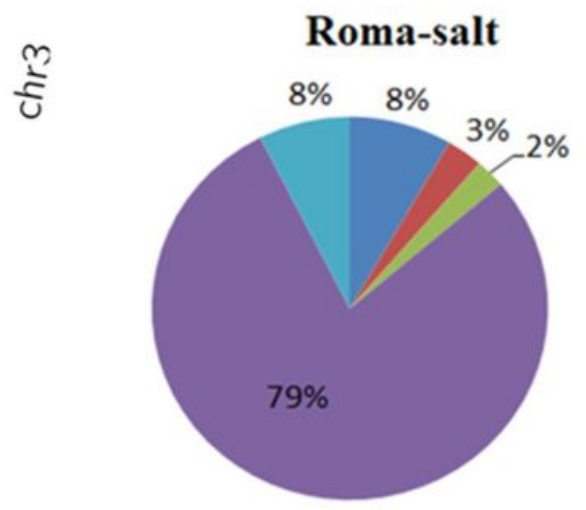

$=\mathrm{i}$
$=\mathrm{j}$
$=\mathrm{o}$
$\mathrm{u}$
$\mathrm{m}$

M-81E
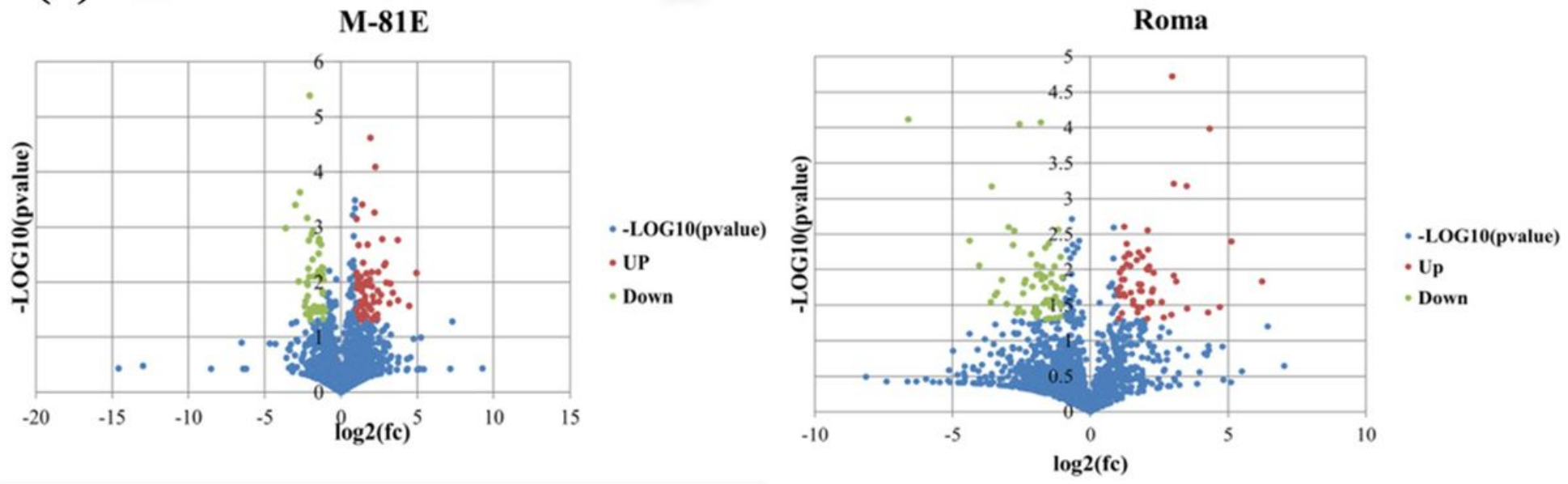

Figure 2

Identification and characterization of DELs. (a) Distribution of IncRNA on the chromosomes. (b) Unique reads mapped to various genomic regions. i: A transfrag falling entirely within a reference intron; j: potentially novel isoform (fragment) with at least one splice junction shared with a reference transcript; 0 : generic exonic overlap with a reference transcript; $u$ : unknown, intergenic transcript; $x$ : exonic overlap with reference on the opposite strand. (c) Number of DELs identified in M-81E-CK vs M-81E-salt and Roma-CK vs Roma-salt. Among them, the blue points indicate the DELs $(-1>\log 2(\mathrm{fc})>1)$, the green points indicate 
the downward adjustment of DELs $(\log 2(\mathrm{fc})<-1, P \leq 0.05)$, and the red points indicate the Upward adjustment of DELs $(\log 2(\mathrm{fc})>1, P \leq 0.05)$.

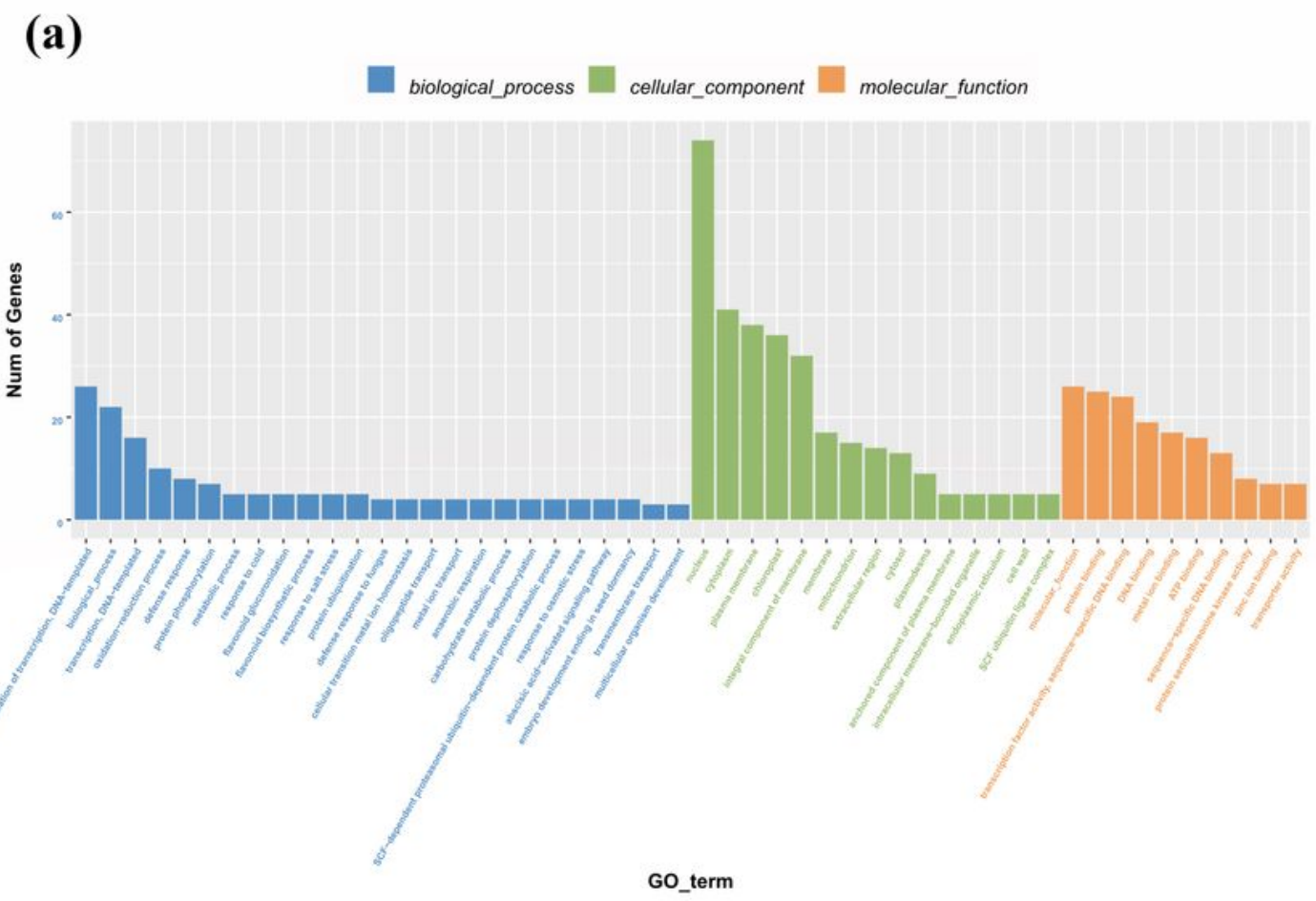

(b)

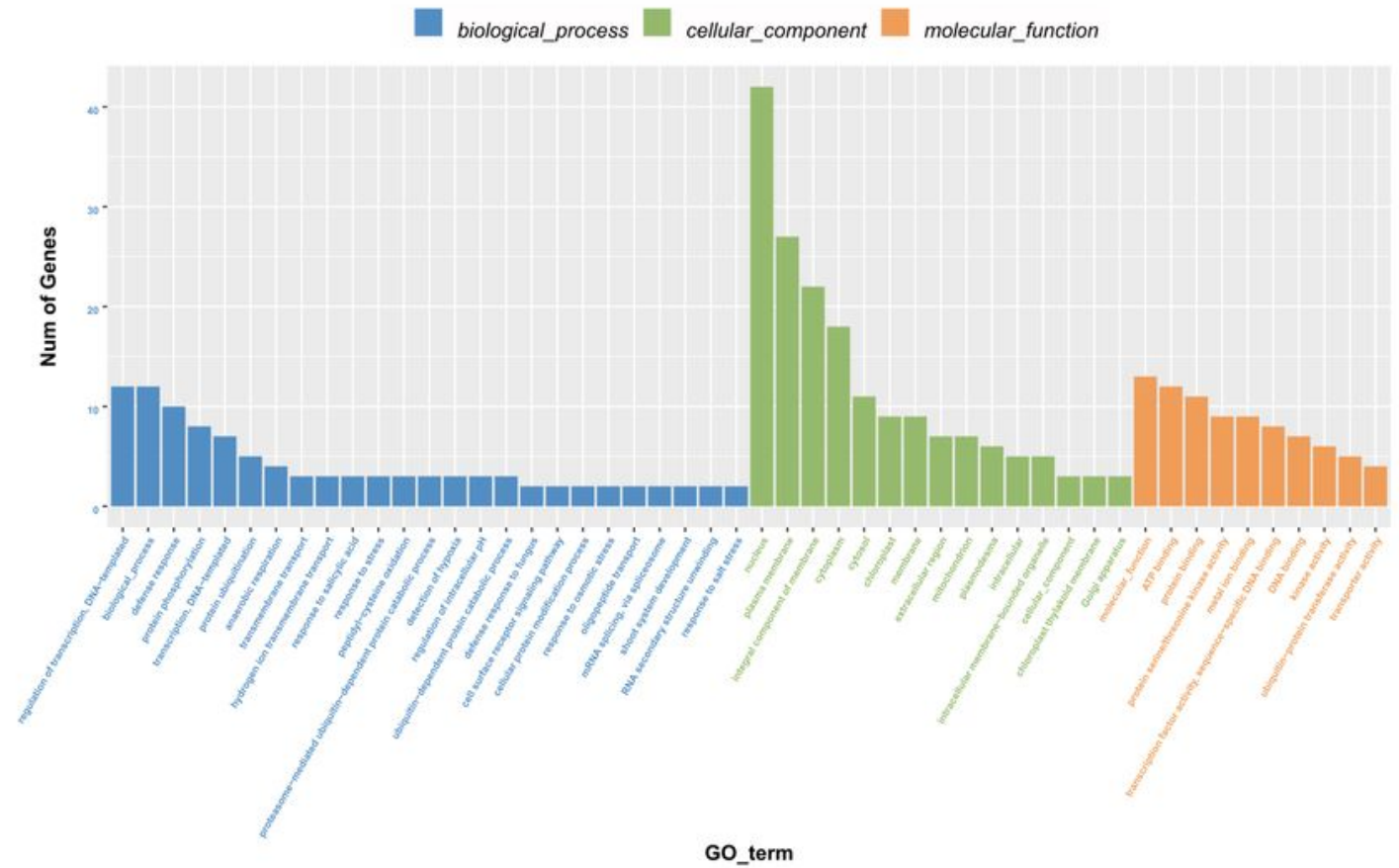

Figure 3

Gene ontology enrichment of ceRNA-regulated protein-coding genes. 
(a)

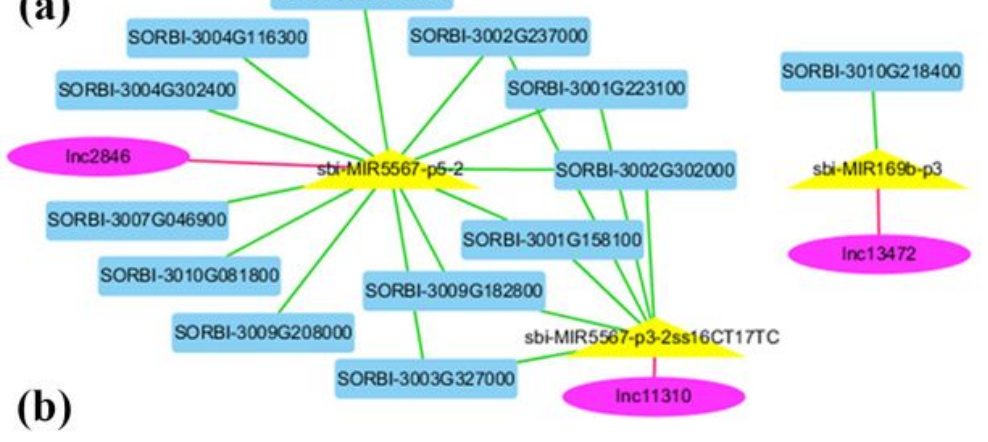

(b)

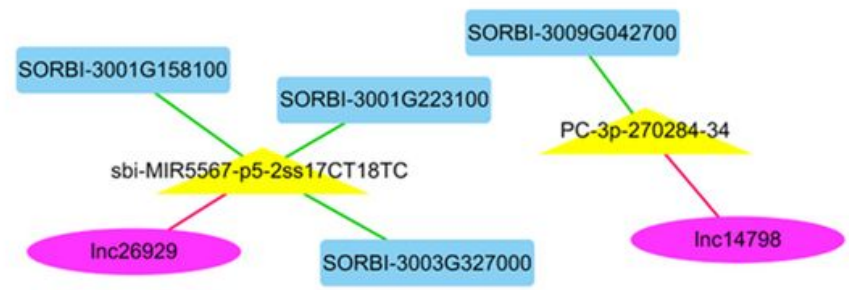

(c) IncRNA

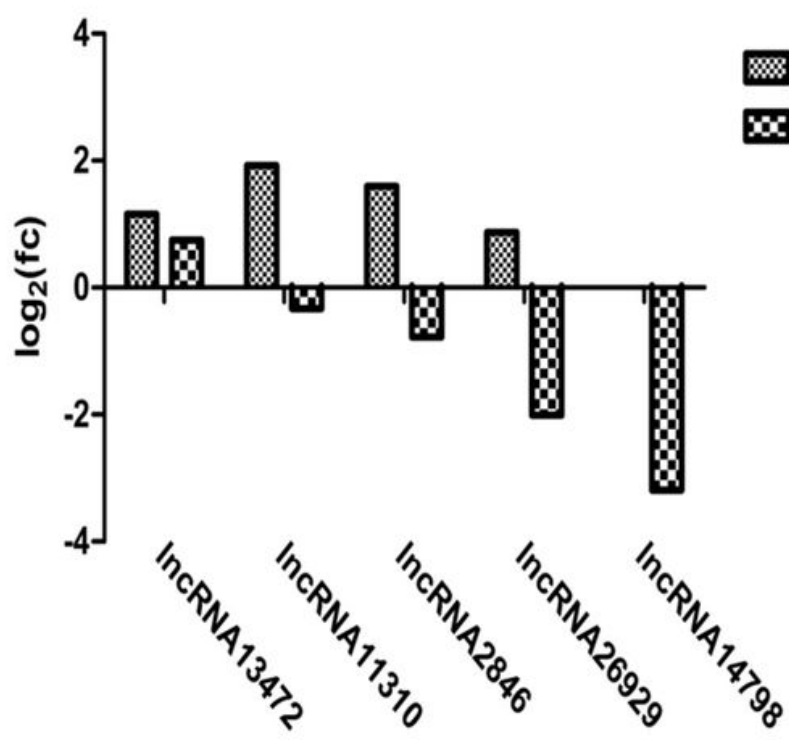

\section{Figure 4}

A ceRNA network enriched in salt-tolerant pathways in M-81E (a) and Roma (b). Red, yellow, and blue nodes represent IncRNAs, miRNAs, and mRNAs, respectively. Green edges represent miRNA-target interactions, while blue edges represent a competitive relationship. (c) Expression of five unknown IncRNAs in M-81E and Roma. 
(a)

biological_process $\square$ cellular_component $\square$ molecular_function
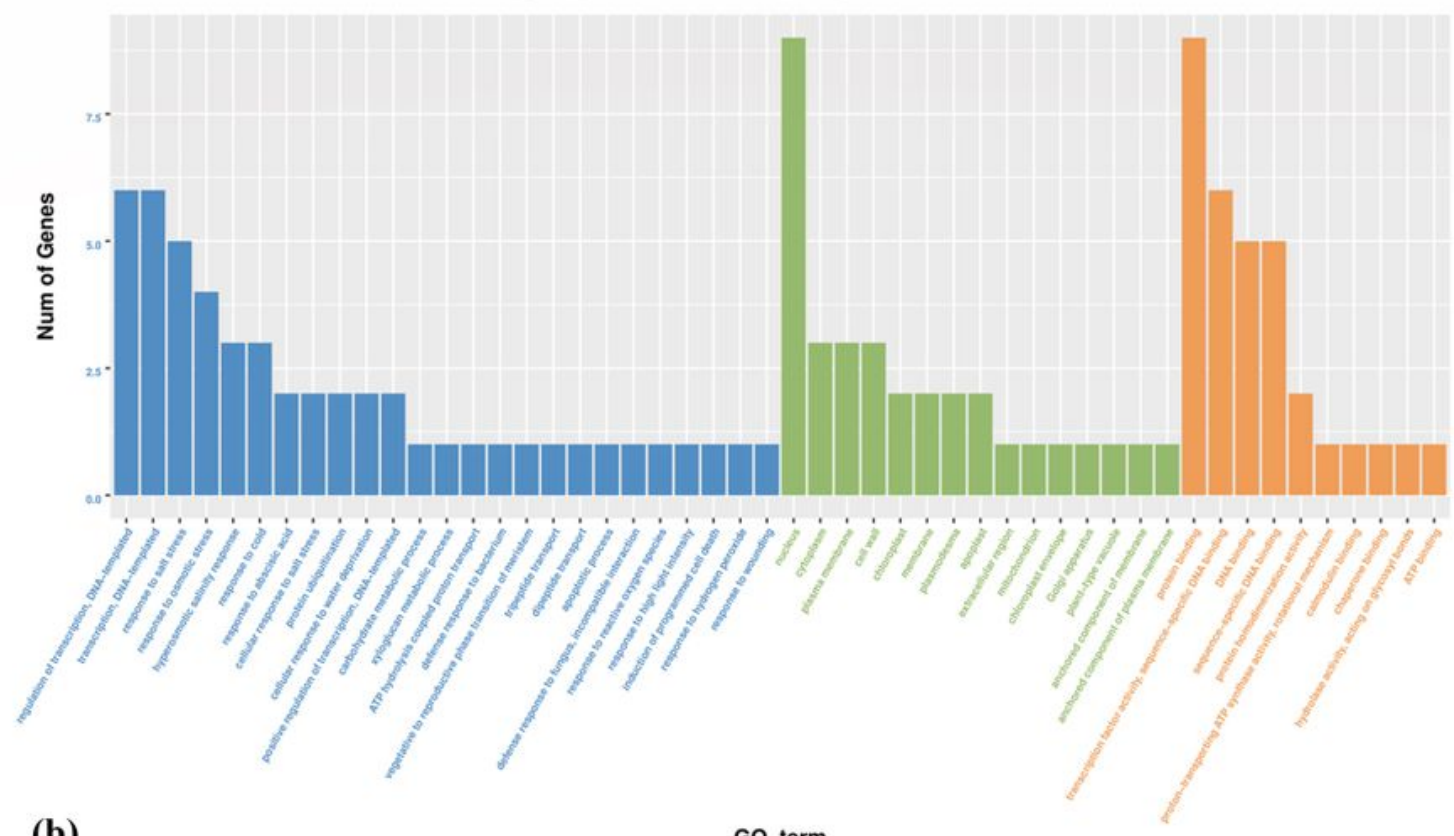

(b)

Go_term

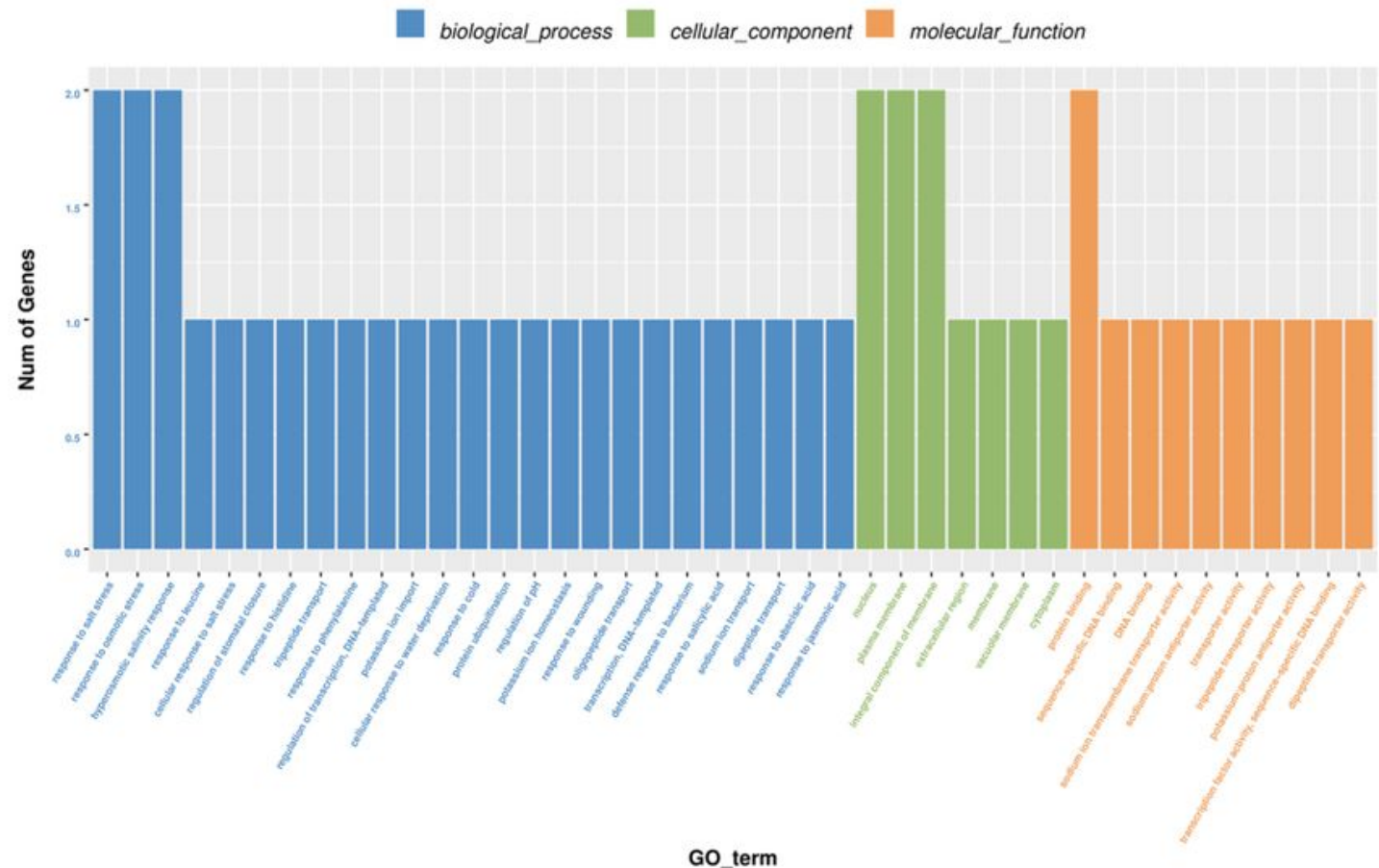

Figure 5

Gene ontology enrichment of ceRNA-regulated protein-coding genes. The results summarize the three main categories: Biological Processes, Molecular Functions and Cellular Components. 
(a)
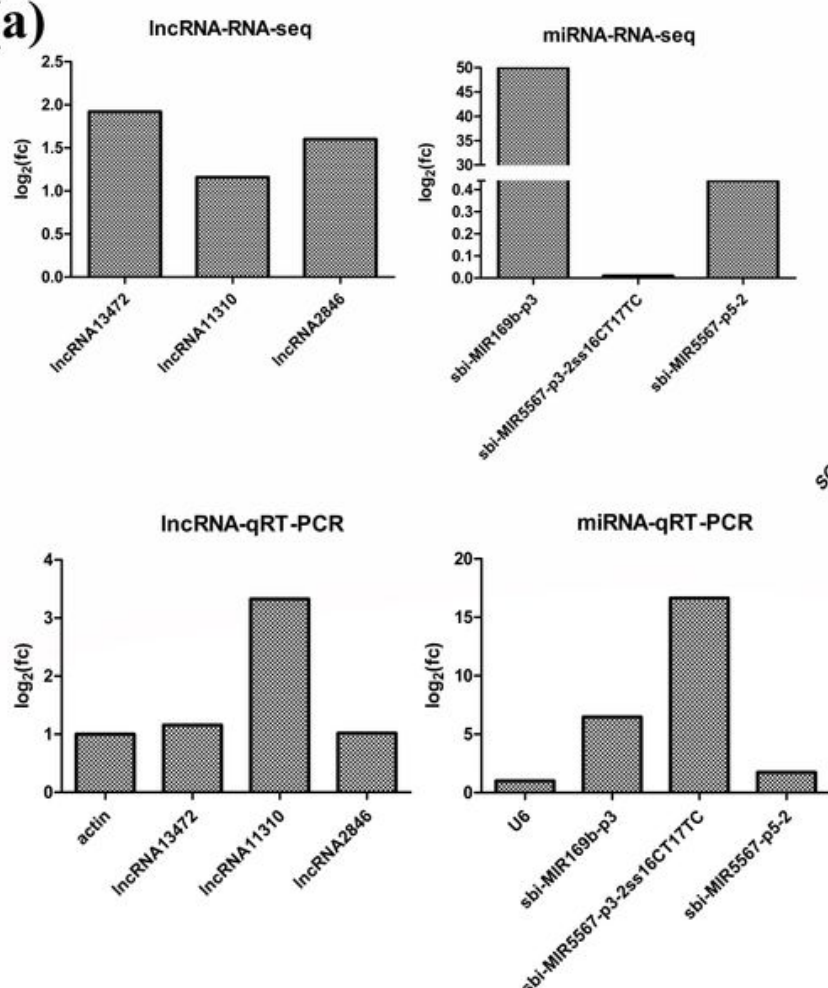

(b)
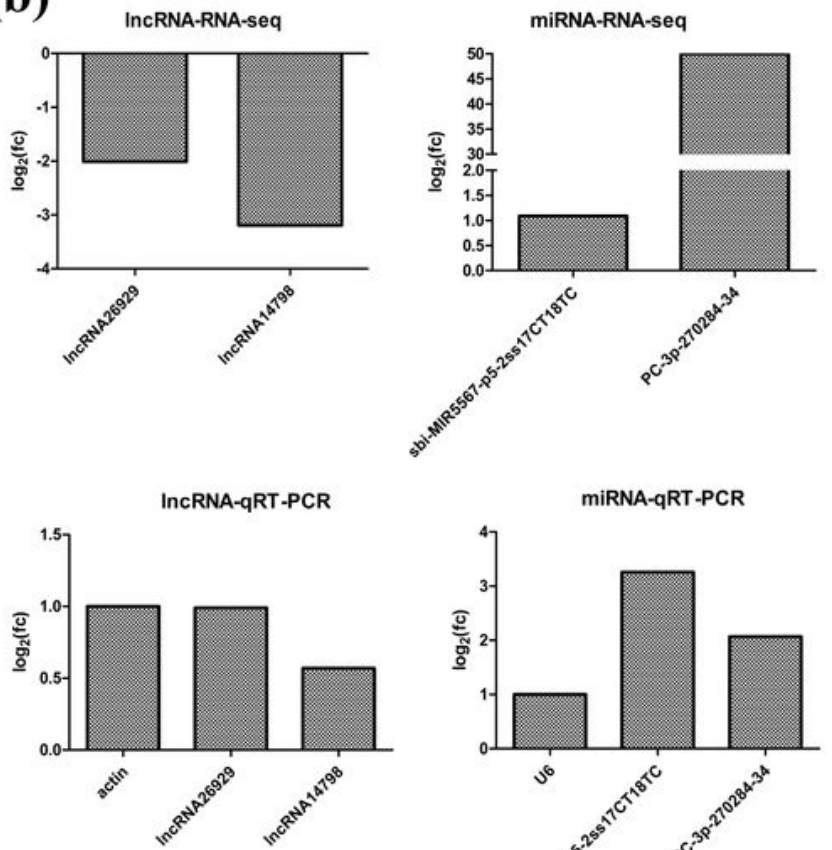

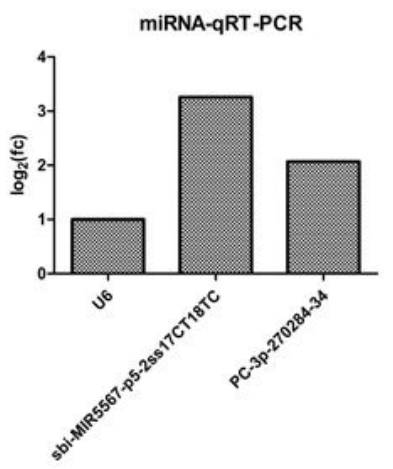

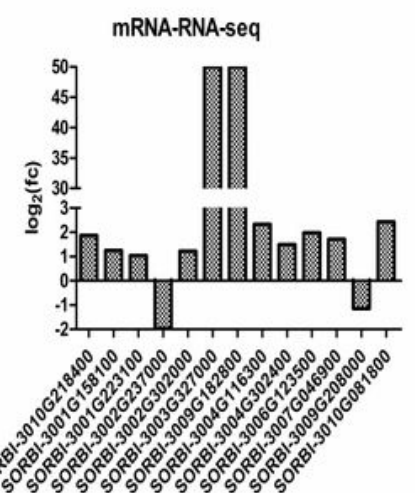

mRNA-qRT-PCR
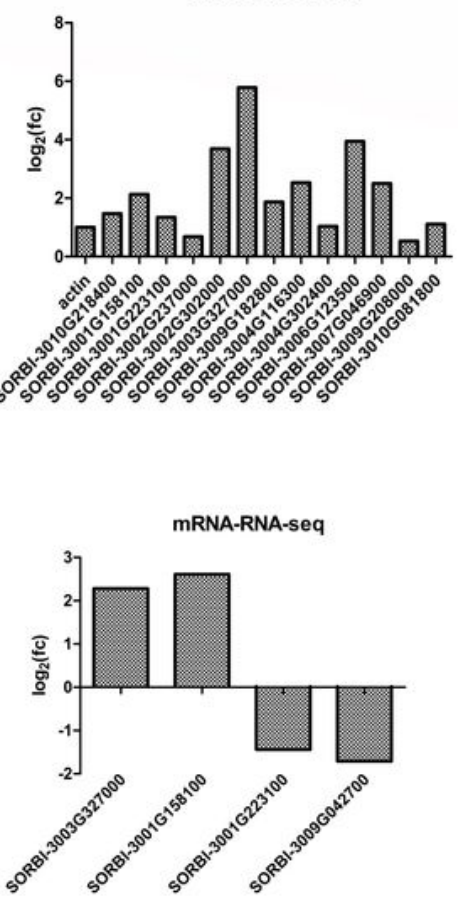

MRNA-qRT-PCR

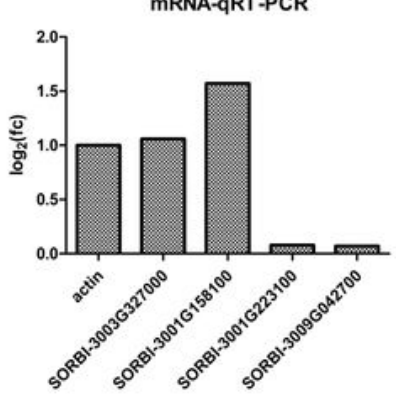

Figure 6

Quantitative RT-PCR analysis and RNA-seq results of ceRNA regulatory networks in M-81E (a) and Roma (b). Three biological replicates were prepared for each of these samples. Actin is the endogenous reference gene for IncRNAs and mRNAs, and U6 is the endogenous reference gene for miRNAs.

\section{Supplementary Files}


This is a list of supplementary files associated with this preprint. Click to download.

- Fig.S1.tif

- Fig.S2.pdf

- SupplementalTables.docx 